\title{
RAPID REVERSAL BY NALOXONE OF THE CHRONIC EFFECTS OF MORPHINE ON RAT LIVER AND BRAIN TRYPTOPHAN METABOLISM
}

\author{
A.A.-B. BADAWY \& M. EVANS
}

South Glamorgan Health Authority, Addiction Unit Research Laboratory, Whitchurch Hospital, Cardiff CF4 7XB

The chronic morphine-induced inhibition of rat liver tryptophan pyrrolase activity and the resultant increases in tryptophan availability to the brain and brain 5 hydroxytryptamine (5-HT) synthesis are reversed within $10 \mathrm{~min}$ after naloxone administration. The possible involvement of hepatic tryptophan metabolism in morphine dependence is briefly discussed.

Introduction Chronic administration of four drugs of dependence (including morphine) enhances rat brain 5-hydroxytryptamine (5-HT) synthesis by increasing the availability of circulating tryptophan to the brain (Badawy, Punjani \& Evans, 1979; 1981a) secondarily to the NADPH-mediated inhibition of liver tryptophan pyrrolase (tryptophan 2,3dioxygenase, EC 1.13.11.11) activity (Badawy \& Evans, 1975a,b). Naloxone, which is presumed to be a specific opiate antagonist, is capable of reversing the above changes in liver and brain tryptophan metabolism caused not only by morphine (Badawy et al., 1981a), but also by ethanol, nicotine or phenobarbitone (Badawy, Evans \& Punjani, 1981b). In most of these latter studies, experiments were performed at $2 \mathrm{~h}$ after naloxone administration, and although this antagonist reverses the chronic morphine-induced inhibition of liver pyrrolase activity as early as $15 \mathrm{~min}$ after administration, its possible reversal of the morphine enhancement of brain 5-HT synthesis at this or earlier time intervals has not been examined. Such a possible early reversal may be of interest from two chronological viewpoints: (1) relationship with the well known ability of naloxone to cause a rapid development of the opiate-withdrawal syndrome; (2) the speed with which changes in hepatic tryptophan metabolism can influence that in brain. We show in the present communication that the chronic morphine-induced changes in rat liver and brain tryptophan metabolism can be reversed as early as $10 \mathrm{~min}$ after naloxone administration and that such biochemical effects coincide with the production of morphine withdrawal under our experimental conditions.

Methods All details concerning animals (male Wistar rats), chemicals, chronic morphine administ- ration (in drinking water for 3 weeks), doses and chemical, enzymatic and other determinations have been described previously (Badawy et al., 1981a,b).

Results Average daily intake of morphine sulphate in drinking water was $50 \mathrm{mg} / \mathrm{kg}$ body wt. Under these conditions, our rats exhibited tolerance to, and physical dependence on, the drug.

As shown in Table 1, chronic morphine administration inhibited the holoenzyme, total enzyme and apoenzyme activities of rat liver tryptophan pyrrolase by 21,50 and $76 \%$ respectively $(P=0.05-0.001)$ and increased the concentrations of liver, free (ultrafiltrable) serum, total (acidsoluble) serum and brain tryptophan and those of brain 5-HT and its major metabolite 5hydroxyindol-3-ylacetic acid (5-HIAA) by 26,30 , $27,27,18$ and $25 \%$ respectively $(P<0.001)$. The drug treatment did not alter significantly tryptophan binding to serum proteins (expressed as the percentage free serum tryptophan), serum glucose or corticosterone concentration. These morphineinduced changes in liver pyrrolase activity and in tryptophan and hydroxyindole concentrations in liver, serum and/or brain were all reversed $10 \mathrm{~min}$ after naloxone administration; the values then obtained did not differ significantly from those observed in saline-treated control rats. In addition, naloxone caused a $20 \%$ increase $(P<0.01)$ in serum corticosterone concentration in morphinedependent rats.

In experiments not described here, it was found that the chronic morphine-induced inhibition of liver pyrrolase activity was only partially reversed $5 \mathrm{~min}$ after naloxone administration.

The results in Table 1 also show that naloxone administration to control rats inhibited the holoenzyme, total enzyme and apoenzyme activities of liver tryptophan pyrrolase by 26,40 and $52 \%$ respectively $(P=0.02-0.001)$ but exerted no significant effects on any of the other parameters examined. Further experiments with naloxone in control rats (details of which will be given elsewhere) revealed that the antagonist inhibits pyrrolase activity maximally at $10 \mathrm{~min}$ by two mechanisms, one of which involves 
Table 1 Reversal by naloxone of the chronic effects of morphine on rat liver and brain tryptophan metabolism

\begin{tabular}{|c|c|c|c|c|}
\hline \multirow[b]{2}{*}{ Determination } & \multicolumn{2}{|c|}{ Saline } & \multicolumn{2}{|c|}{ Naloxone } \\
\hline & $\begin{array}{l}\text { Control } \\
\text { (1) }\end{array}$ & $\begin{array}{c}\text { Morphine } \\
\text { (2) }\end{array}$ & $\begin{array}{l}\text { Control } \\
\text { (3) }\end{array}$ & $\begin{array}{c}\text { Morphine } \\
\text { (4) }\end{array}$ \\
\hline \multicolumn{5}{|l|}{ Liver pyrrolase: } \\
\hline Holoenzyme & $1.90 \pm 0.14$ & $1.50 \pm 0.08 \dagger$ & $1.40 \pm 0.05^{*}$ & $1.70 \pm 0.10^{*}$ \\
\hline Total enzyme & $4.00 \pm 0.12$ & $2.00 \pm 0.11^{* * *}$ & $2.40 \pm 0.07^{* * *}$ & $4.10 \pm 0.19^{* * *}$ \\
\hline Apoenzyme & $2.10 \pm 0.07$ & $0.50 \pm 0.02^{* * *}$ & $1.00 \pm 0.10^{* * *}$ & $2.40 \pm 0.15^{* * *}$ \\
\hline Liver Trp & $6.42 \pm 0.13$ & $8.10 \pm 0.20^{* * *}$ & $6.20 \pm 0.10$ & $6.78 \pm 0.22 \dagger$ \\
\hline Free serum Trp & $1.19 \pm 0.06$ & $1.55 \pm 0.03^{* * *}$ & $1.21 \pm 0.06$ & $1.37 \pm 0.04$ \\
\hline Total serum Trp & $22.51 \pm 0.70$ & $28.58 \pm 0.67^{* * *}$ & $22.13 \pm 0.31$ & $23.70 \pm 0.40^{*}$ \\
\hline Free serum Trp (\%) & $5.29 \pm 0.31$ & $5.42 \pm 0.27$ & $5.47 \pm 0.27$ & $5.78 \pm 0.26$ \\
\hline Brain Trp & $2.37 \pm 0.07$ & $3.00 \pm 0.07^{* * *}$ & $2.45 \pm 0.04$ & $2.45 \pm 0.12$ \\
\hline Brain 5-HT & $0.55 \pm 0.007$ & $0.65 \pm 0.005^{* * *}$ & $0.53 \pm 0.006$ & $0.55 \pm 0.008$ \\
\hline Brain 5-HIAA & $0.36 \pm 0.003$ & $0.45 \pm 0.003^{* * *}$ & $0.37 \pm 0.004$ & $0.38 \pm 0.010$ \\
\hline Serum glucose & $161.00 \pm 4.00$ & $161.00 \pm 2.00$ & $156.00 \pm 3.00$ & $161.00 \pm 5.00$ \\
\hline Serum corticosterone & $66.50 \pm 0.70$ & $66.50 \pm 0.50$ & $65.20 \pm 2.70$ & $78.50 \pm 2.90^{* *}$ \\
\hline
\end{tabular}

Rats were chronically treated with morphine sulphate in drinking water for 3 weeks. Both control and morphinetreated rats received, $10 \mathrm{~min}$ before death, an intraperitoneal injection of either naloxone hydrochloride (1 mg/kg body wt.) or an equal volume $(2.5 \mathrm{ml} / \mathrm{kg}$ body wt.) of $0.9 \%(\mathrm{w} / \mathrm{v}) \mathrm{NaCl}$ solution (saline). Pyrrolase activities are expressed in $\mu \mathrm{mol}$ of kynurenine formed/h per $\mathrm{g}$ wet wt. of liver (means $\pm \mathrm{s}$.e. for each group of four rats), whereas all other determinations are means \pm s.e. for each group of six rats and are expressed as follows: tryptophan (Trp) and hydroxyindoles $(\mu \mathrm{g} / \mathrm{ml}$ of serum or per $\mathrm{g}$ wet $\mathrm{wt}$. of tissue); glucose $(\mathrm{mg} / \mathrm{dl})$; corticosterone $(\mu \mathrm{g} / \mathrm{litre})$; free serum tryptophan (\%). The values in columns 2 and 3 are compared with those in column 1 , whereas those in column 4 are compared with those in column 3 , and the significance of differences is indicated as follows: $† P<0.05 ;{ }^{*} P<0.02$; ${ }^{* *} P<0.01 ;{ }^{* * *} P<0.001$.

prevention of the conjugation of the apoenzyme with its cofactor haem.

Discussion The effects of chronic morphine administration on rat liver and brain tryptophan metabolism described here (Table 1) confirm previous findings (Badawy et al., 1981a) and are consistent with the drug enhancing brain 5-HT synthesis by increasing tryptophan availability to the brain secondarily to the inhibition of liver pyrrolase activity. Badawy et al. (1981a) have also presented further evidence strongly supporting this conclusion and also the inverse relationship between liver pyrrolase activity and brain 5-HT synthesis. The ability of naloxone to reverse fully, at $10 \mathrm{~min}$, all the above effects of morphine on liver and brain tryptophan metabolism (Table 1) and the finding (Young \& Sourkes, 1975) that the liver can degrade all its tryptophan within 7.5 min suggest that pyrrolase exerts a rapid influence on both intra- and extra-hepatic tryptophan metabolism.

The first withdrawal symptom (diarrhoea) exhibited by our rats occurs at $7 \mathrm{~min}$ after naloxone administration (unpublished observation) and is therefore preceded by at least 2 min by some partial reversal of the morphine inhibition of liver pyrrolase activity (see the text). These findings together with the rapid influence of the liver on tryptophan disposition (see above) and the possible involvement of 5-HT in morphine tolerance and dependence (see e.g. Way, 1972; Way, Ho \& Loh, 1974) raise the possibility that changes in liver tryptophan metabolism may be involved in the above actions of morphine. This possibility is subject to experimental evaluation by modification of hepatic tryptophan metabolism by agents other than naloxone.

The finding (Table 1) that naloxone increases serum corticosterone concentration in morphinedependent rats at $10 \mathrm{~min}$ is similar to that obtained at $2 \mathrm{~h}$ after administration of this antagonist to rats chronically pretreated with morphine or other drugs of dependence, and may be explicable, as discussed previously (Badawy et al., 1981b) in relation to the role of 5-HT in glucocorticoid release mechanisms.

We thank the Welsh Office for a project grant, Miss Nazeera F. Punjani and Mr C.J. Morgan for skilful assistance and Mr A. Dacey for animal maintenance. 


\section{References}

BADAWY, A.A.-B. \& EVANS, M. (1975a). The effects of ethanol on tryptophan pyrrolase activity and their comparison with those of phenobarbitone and morphine. Adv. exp. Med. Biol., 59, 229-251.

BADAWY, A.A.-B. \& EVANS, M. (1975b). The effects of acute and chronic nicotine hydrogen $(+)$-tartrate administration and subsequent withdrawal on rat liver tryptophan pyrrolase activity and their comparison with those of morphine, phenobarbitone and ethanol. Biochem. J., 148, 425-432.

BADAWY, A.A.-B., EVANS, M. \& PUNJANI, N.F. (1981b). Reversal by naloxone of the effects of chronic administration of drugs of dependence on rat liver and brain tryptophan metabolism. Br. J. Pharmac., 74, 489-494.

BADAWY, A.A.-B., PUNJANI, N.F. \& EVANS, M. (1979). Enhancement of rat brain tryptophan metabolism by chronic ethanol administration and possible involve- ment of decreased liver tryptophan pyrrolase activity. Biochem. J., 178, 575-580.

BADAWY, A.A.-B., PUNJANI, N.F. \& EVANS, M. (1981a). The role of liver tryptophan pyrrolase in the opposite effects of chronic administration and subsequent withdrawal of drugs of dependence on rat brain tryptophan metabolism. Biochem. J., 196, 161-170.

WAY, E.L. (1972). The role of serotonin in morphine effects. Fedn Proc., 31, 113-120.

WAY, E.L., HO, I.K. \& LOH, H.H. (1974). Brain 5hydroxytryptamine and cyclic AMP in morphine tolerance and dependence. Adv. Biochem. Psychopharmac., 10, 219-231.

YOUNG, S.N. \& SOURKES, T.L. (1975). Tryptophan catabolism by tryptophan pyrrolase in rat liver - the effects of tryptophan loads and changes in tryptophan pyrrolase activity. J. biol. Chem., 250, 5009-5014.

(Received August 17, 1981.) 